\title{
Baroreflex sensitivity in hypertension during beta-adrenergic blockade
}

\author{
R. T. KREDIET AND A. J. DUNNING \\ From the University Department of Medicine, Binnengasthuis, Amsterdam, The Netherlands
}

SUMMARY Baroreceptor function was measured in 18 patients with essential hypertension by plotting the change in pulse interval against a phenylephrine-induced transient rise in systolic blood pressure. The influence of propranolol (160 mg daily for at least 4 weeks) on this function and on heart rate after maximal exercise was studied and correlated with the plasma propranolol level. In 13 out of the 18 patients only baroreflex resetting occurred with no change in sensitivity during propranolol administration. A definite correlation was found between the degree of beta-adrenergic blockade, expressed as the reduction in maximal exercise heart rate and the change in mean arterial pressure. No relation could be shown between plasma propranolol steady state levels and these changes. The fall in blood pressure during beta-adrenergic blockade with a low dosage of propranolol apparently does not depend on changed baroreflex sensitivity, but on the intrinsic action of this drug on beta-receptors.

Beta-adrenergic blocking agents lower blood pressure effectively, but their mode of action remains obscure. The antihypertensive effect has variously been ascribed to a reduction in cardiac output (Frohlich et al., 1968) or renin activity (Bühler et al., 1972), but the relative importance of these changes has been disputed. Theories based on a central mechanism of action remain controversial (Offerhaus and van Zwieten, 1974; Meyers et al., 1975), while Prichard proposed that a gradual conditioning of the baroreceptors by the damping of pressor responses to regulate the blood pressure at a lower level might be the most likely explanation (Prichard and Gillam, 1966).

We therefore studied the baroreflex sensitivity in hypertensive patients before and during treatment with a beta-adrenergic blocking drug (propranolol). Such sensitivity can be measured repeatedly by plotting the rise in blood pressure after a bolus injection of phenylephrine against the concomitant decrease in heart rate (Bristow et al., 1969; Smyth er al., 1969). Reflex changes were correlated with the degree of beta-adrenergic blockade, determined by the heart rate reduction during exercise and the plasma levels of propranolol.

\section{Patients and methods}

Baroreflex sensitivity was measured before and after

Received for publication 30 December 1977
4 to 6 weeks of treatment with propranolol $80 \mathrm{mg}$ orally twice daily in 18 outpatients who gave informed consent. All had essential hypertension (diastolic pressure between 100 and $130 \mathrm{mmHg}$ ). Their ages were 25 to 69 years, mean 43 . All other medication was stopped two weeks before the first measurement and patients were advised to moderate their dietary sodium intake.

Intra-arterial blood pressure and electrocardiograms were recorded simultaneously on a multichannel ink-jet writer at a paper speed of $50 \mathrm{~mm} / \mathrm{s}$.

Between 3 and 5 bolus injections of phenylephrine, $200 \mu \mathrm{g}$, were given through an intravenous cannula in an antecubital vein. The interval between the injections always exceeded 5 minutes. During the rapid rise in blood pressure after injection, baroreflex sensitivity was calculated by plotting the $R R$ interval against the systolic pressure of the preceding beat. Measurements were made from the moment arterial pressure began to rise acutely until it reached its peak, and the linear correlation between these points was then calculated using the method of least squares. Reflex sensitivity was expressed as the slope of the regression line, and the result was included only if the $P$ value was less than 0.05 and the correlation coefficient was greater than $0 \cdot 60$. Occasionally these conditions were not met.

Baroreceptor function can be modified in two ways. When the slope of the relation between arterial pressure and pulse interval remains unaltered, the regression lines before and during 
treatment are parallel, indicating that baroreflex sensitivity is unchanged. The shift observed is called resetting. On the other hand, a change in the slope of the regression line during treatment is indicative of an alteration in the sensitivity of the reflex arc. A combination of resetting and a change in sensitivity is also possible. For practical reasons in our experiments resetting was calculated as the percentage change in the systolic arterial pressure at an RR interval of $1000 \mathrm{~ms}$.

All patients performed a multistage maximal exercise treadmill test according to the Bruce protocol (Bruce et al., 1963) before and during treatment. The degree of beta-adrenergic blockade was calculated as the percentage reduction in heart rate at maximal exercise during treatment with propranolol.

After 4 to 6 weeks of treatment plasma propranolol levels were measured in 16 patients in the fasting state and $2,3,4,5$, and 6 hours after administration of propranolol $80 \mathrm{mg}$ orally. The mean steady state concentration was calculated from the area under the curve, divided by the dosage interval; the plasma propranolol concentration was determined by a modified fluorimetric method (Offerhaus and van der Vecht, 1976).

Statistical analysis was performed using the $t$ test for unpaired data, with Bessel correction for small numbers.

\section{Results}

As expected, both mean arterial pressure and heart rate at rest and during exercise decreased after 4 to 6 weeks of propranolol, $160 \mathrm{mg}$ daily (Table 1). Baroreflex sensitivity did not change significantly in the group as a whole, though in 4 patients there was a significant increase above control values

Table 1 Effects of propranolol on haemodynamics (mean $\pm S E M)$ in 18 patients

\begin{tabular}{lccl}
\hline & $\begin{array}{l}\text { Before } \\
\text { treatment }\end{array}$ & $\begin{array}{l}\text { Propranolol } \\
160 \text { mg/day }\end{array}$ & $\begin{array}{l}\text { Significance } \\
\text { of change }\end{array}$ \\
\hline $\begin{array}{l}\text { Mean arterial } \\
\text { pressure (mmHg) }\end{array}$ & $123 \pm 4$ & $111 \pm 3$ & $\mathrm{P}<0.05$ \\
$\begin{array}{l}\text { Resting heart rate } \\
\text { (b/min) }\end{array}$ & $72 \pm 2$ & $57 \pm 2$ & $\mathrm{P}<0.001$ \\
$\begin{array}{l}\text { Maximal heart rate } \\
\text { during exercise } \\
\text { (b/min) }\end{array}$ & $162 \pm 4$ & $126 \pm 4$ & $\mathrm{P}<0.001$ \\
$\begin{array}{l}\text { Baroreceptor reflex } \\
\text { sensitivity (ms/mmHg) }\end{array}$ & $8.53 \pm 1.18$ & $11.17 \pm 2.06 \mathrm{NS}$ \\
$\begin{array}{l}\text { Systolic arterial } \\
\text { pressure at RR inter- }\end{array}$ & $206 \pm 10$ & $149 \pm 7$ & $\mathrm{P}<0.001$ \\
$\begin{array}{l}\text { val of 1000 ms (mmHg) } \\
\text { Phenylephrine induced } \\
\text { rise in systolic } \\
\text { arterial pressure } \\
\text { (mmHg) }\end{array}$ & $40 \pm 3$ & $51 \pm 3$ & $\mathrm{P}<0.05$ \\
\hline
\end{tabular}

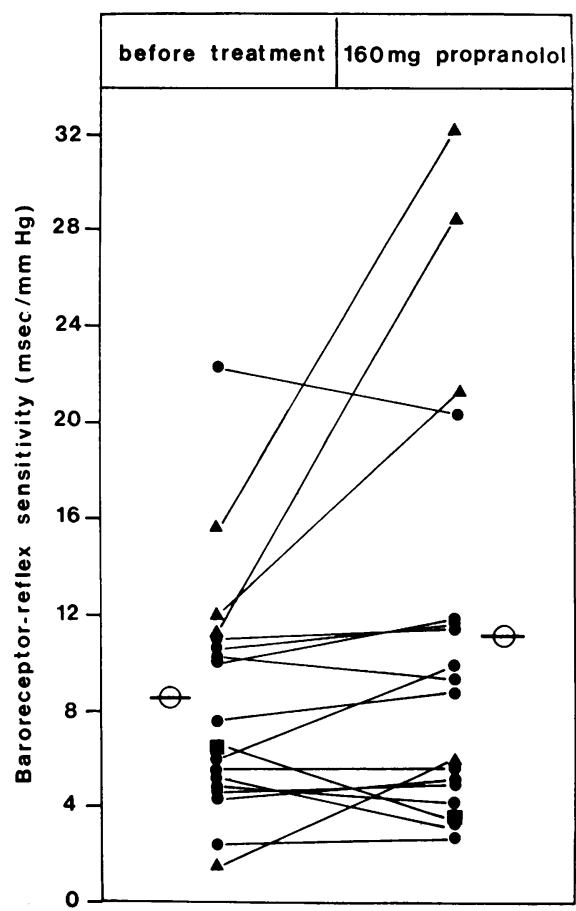

Fig. 1 Baroreceptor-reflex sensitivity before and during propranolol therapy. Four patients show increased sensitivity $(\boldsymbol{\Delta}), 13$ no significant change $(O)$, and 1 a decrease in sensitivity ( $\square$. The open circles represent the mean values for all patients.

(group B) (Fig. 1). In 13 patients (group A) there was only resetting of the baroreceptors, since propranolol lowered heart rate and blood pressure equally. One patient showed a decrease in baroreceptor sensitivity. The 4 patients with increased sensitivity also showed baroreceptor resetting (Fig. 2). When resetting was plotted against the reduction in maximal heart rate or mean arterial pressure, two linear relations were obtained (Fig. 3), showing the relative contributions of changes in heart rate and blood pressure to such resetting. There was no significant difference between groups A and B with regard to age, initial mean arterial pressure, pretreatment baroreflex sensitivity, heart rate, and blood pressure reduction during propranolol treatment, or in the mean steady state concentration of plasma propranolol (64 \pm 8 versus $84 \pm 19 \mathrm{ng} / \mathrm{ml}$, NS). However, in group $A$ the transient rise in blood pressure after phenylephrine was augmented during propranolol treatment, but this phenomenon was not seen in the 4 patients with both resetting and increased sensitivity (Table 2 ).

In all patients an inverse correlation was found, 

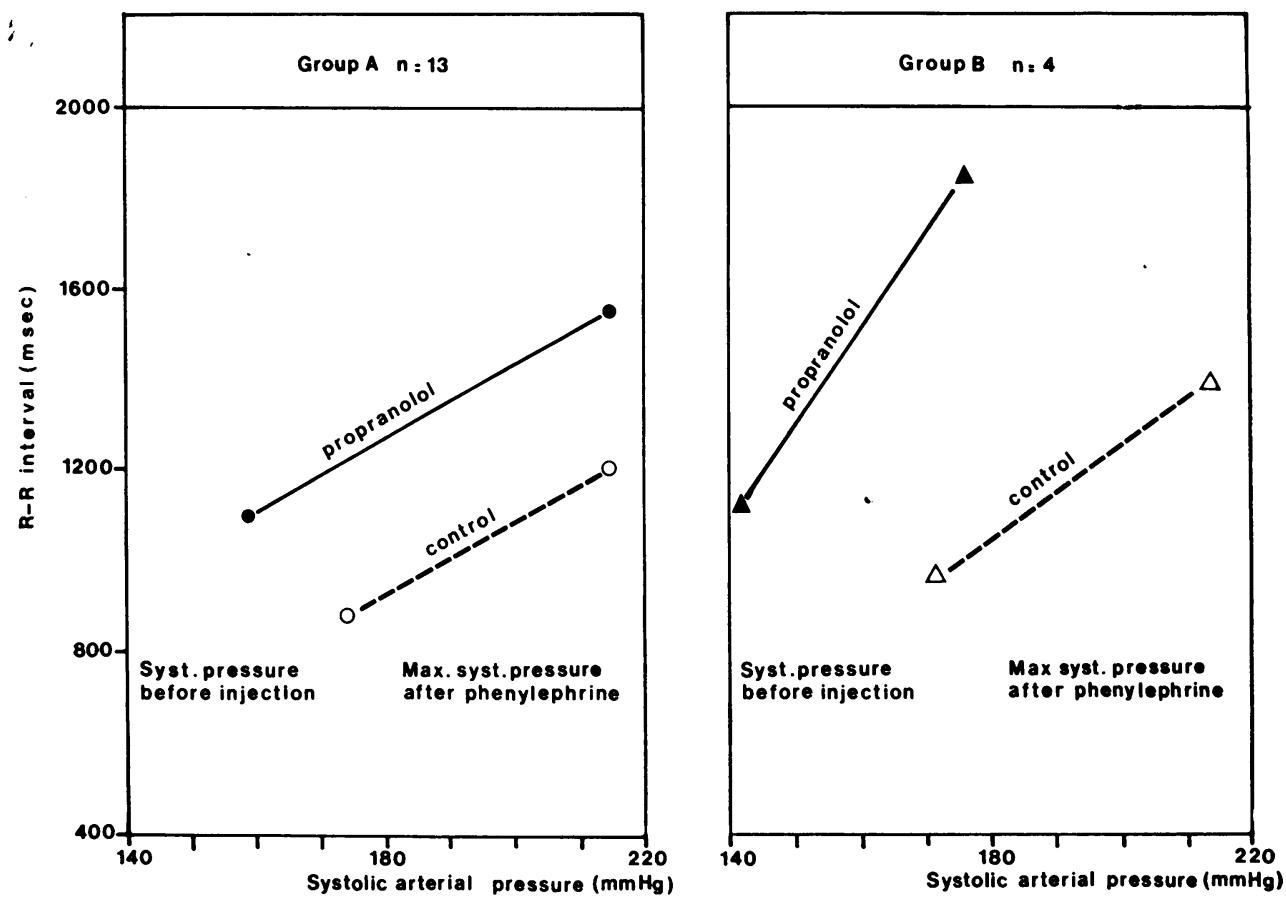

Fig. 2 Influence of propranolol on baroreceptor reflex function. The slope of the lines represents the means of baroreceptor reflex sensitivities before (open symbols) and during (closed symbols) propranolol treatment. In group $A(O)$ the slopes are not significantly different and the lines are parallel (resetting). In group $B(\Delta)$ there is a significant $(P<0.05)$ difference between the slopes (resetting and change in sensitivity).

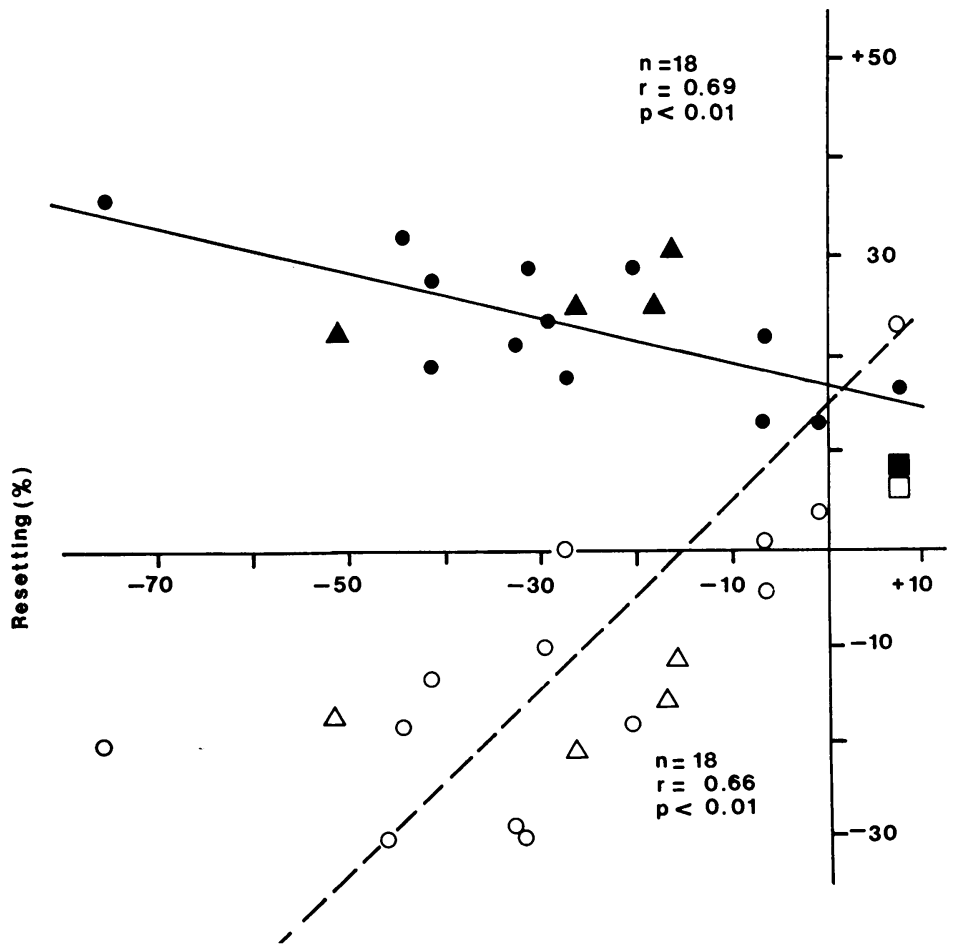

Fig. 3 Relation between resetting versus beta-blocking and antihypersensitive properties of propranolol. In all 18 patients a correlation was found between the degree of resetting versus the percentage reduction in maximal heart rate during exercise (closed symbols) and the change in mean arterial pressure (open symbols). The form of the symbols refers to Fig. 1. 
Table 2 Response to alpha-adrenergic stimulation in group $A$ and $B$ before and during propranolol treatment (mean $\pm S E M)$

\begin{tabular}{llll}
\hline & $\begin{array}{l}\text { Group } A \\
n=13\end{array}$ & $\begin{array}{l}\text { Group B } \\
n=4\end{array}$ & \\
\hline $\begin{array}{l}\text { Phenylephrine induced } \\
\text { rise in systolic } \\
\text { arterial pressure } \\
\text { before treament } \\
\text { (mmHg) }\end{array}$ & $39 \pm 2$ & $42 \pm 13$ & NS \\
$\begin{array}{l}\text { Phenylephrine induced } \\
\text { rise in systolic } \\
\text { arterial pressure } \\
\text { during propranolol } \\
160 \text { mg daily (mmHg) }\end{array}$ & $55 \pm 3$ & $33 \pm 6$ & $\mathrm{P}<0.01$ \\
& $\mathrm{P}<0.001$ & $\mathrm{NS}$ & \\
\hline
\end{tabular}

both before and during propranolol treatment, between baroreflex sensitivity and the rise in systolic arterial pressure after phenylephrine $(\mathbf{P}<$ 0.01 ).

Plotting the change in mean arterial pressure during propranolol treatment against the heart rate reduction during maximal exercise yielded a definite linear relation (Fig. 4). No correlation was found between the propranolol mean steady state concentration and the antihypertensive effect or the reduction in heart rate at rest, or during maximal exercise.

\section{Discussion}

The influence of propranolol on baroreceptor function has previously been studied by Pickering $e t$ al. (1972), who found an increase in baroreflex sensitivity after intravenous propranolol in 4 of 5 healthy volunteers. We found no change in the majority of our hypertensive patients during chronic oral treatment with propranolol, using their method of determining baroreflex sensitivity. This finding confirms the results of Simon et al. (1977) who were also unable to find increased sensitivity in their hypertensive patients after propranolol intravenously. The difference between our results and those of Pickering et al. (1972) may be attributable to the low pretreament sensitivity values in our group showing only resetting (group A)-about one-third of those in the healthy volunteers given propranolol intravenously - and to the fact that such values decrease with age and the severity of hypertension. In 3 of our 4 patients who responded with increased sensitivity, the initial value lay far above the mean (Fig. 1).

The propranolol-induced excessive rise in blood pressure after phenylephrine in those patients showing no change in sensitivity may possibly have been the result of unopposed peripheral alphaadrenergic activity. The fact that this rise was absent

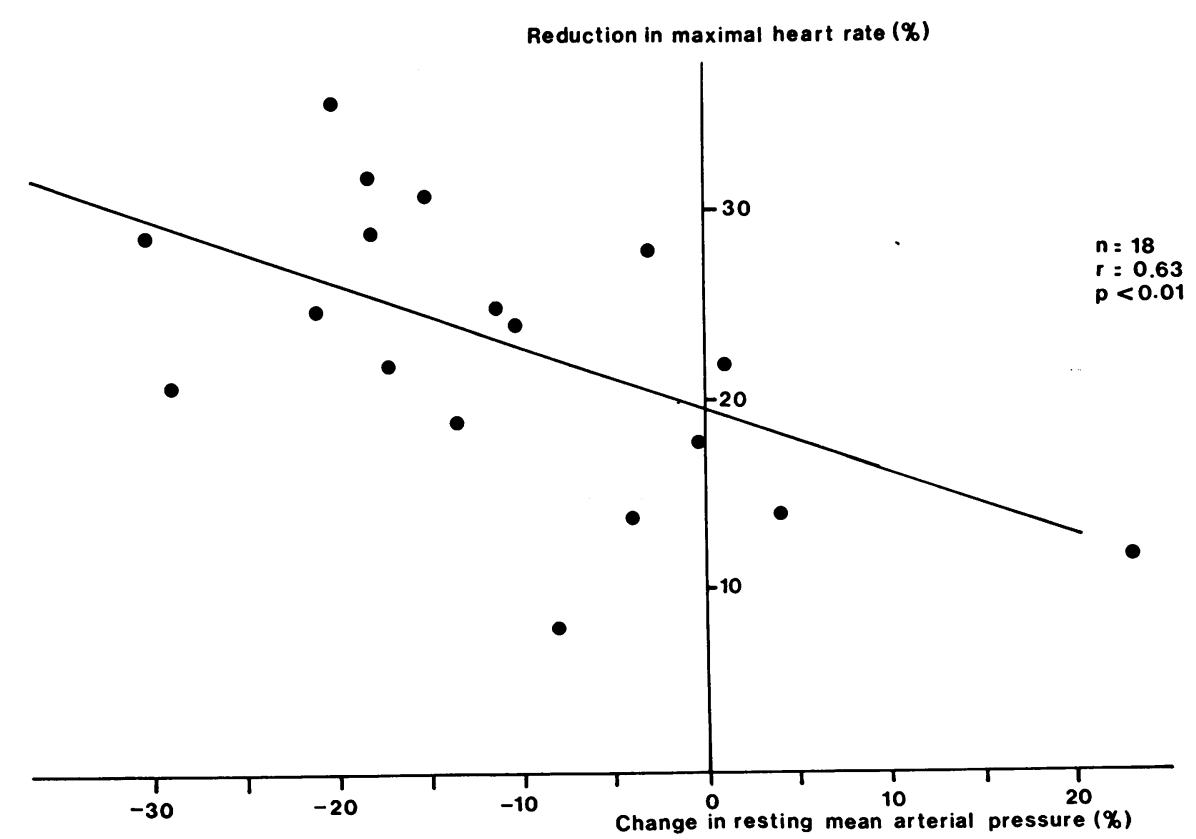

Fig. 4 Correlation between the decrease in blood pressure and the reduction in maximal exercise heart rate during treatment with propranolol. 
in the 4 patients with increased sensitivity on propranolol indicates that a sensitive baroreflex system, functioning normally, protects against an excessive blood pressure response provoked by alpha-adrenergic stimulation, for example by phenylephrine or the cold pressor test (Guazzi et al., 1976).

Although some investigators (Coltart and Shand, 1970; Pine et al., 1975) have reported a linear relation between the degree of beta-adrenergic blockade and the logarithm of the plasma propranolol level, no such relation was found in our study between mean steady state propranolol and its effect on maximal exercise heart rate. This discrepancy might be explained by their method of quantifying beta-blockade in a limited number of healthy volunteers on various dosage schedules or, alternatively, by variations in the metabolic clearance or plasma protein binding of the drug.

Functional beta-adrenergic blockade with a standard propranolol regimen was found to be closely related to its antihypertensive effect and a similar observation was made in a study of hypertensive patients treated with five different betablocking agents (Davidson et al., 1976). In doses that produced similar reductions in exercise tachycardia, all drugs had identical blood pressure lowering activity which was more pronounced on systolic than diastolic pressure and was greatest during exercise.

We, therefore, conclude that the antihypertensive effect of beta-adrenergic blockade is not explained by changes in baroreflex sensitivity; resetting is the major change in function during administration of low dosages of propranolol. The intrinsic action of this drug on the beta-receptors explains adequately the observed fall in blood pressure.

\section{References}

Bristow, J. D., Honour, A. J., Pickering, G. W., Sleight, P., and Smyth, H. S. (1969). Diminished baroreflex sensitivity in high blood pressure. Circulation, 39, 48-54.

Bruce, R. A., Blackman, J. R., Jones, J. W., and Strait, G.
(1963). Exercising testing in adult normal subjects and cardiac patients. Pediatrics, 32, Suppl., 742-756.

Bühler, F. R., Laragh, J. H., Baer, L., Vaughan, E. D., Jr., and Brunner, H. R. (1972). Propranolol inhibition of renin secretion. New England fournal of Medicine, 287, 1209-1214.

Coltart, D. J., and Shand, D. G. (1970). Plasma propranolol levels in the quantitative assessment of beta-adrenergic blockade in man. British Medical fournal, 3, 731-734.

Davidson, C., Thadani, U., Singleton, W., and Taylor, S. H. (1976). Comparison of antihypertensive activity of betablocking drugs during chronic treatment. British Medical Fournal, 2, 7-9.

Frohlich, E. D., Tarazi, R. C., Dustan, H. P., and Page, I. H. (1968). The paradox of beta-adrenergic blockade in hypertension. Circulation, 37, 417-423.

Guazzi, M., Fiorentini, C., Polese, A., Olivari, M. T., and Margrini, F. (1976). Antihypertensive action of propranolol in man; lack of evidence for a neural depressive effect. Clinical Pharmacology and Therapeutics, 20, 304-309.

Meyers, M. G., Lewis, P. J., Reid, J. L., and Dollery, C. T. (1975). Brain concentration of propranolol in relation to hypotensive effect in the rabbit with observations on brain propranolol levels in man. Fournal of Pharmacology and Experimental Therapeutics, 192, 327-335.

Offerhaus, L., and van der Vecht, J. R. (1976). Improved fluorimetric assay of plasma propranolol. British fournal of Clinical Pharmacology, 3, 1061-1062.

Offerhaus, L., and van Zwieten, P. A. (1974). Comparative studies on central factors contributing to the hypotensive action of propranolol, alprenolol and their enantiomers. Cardiovascular Research, 8, 488-495.

Pickering, T. G., Gribbin, B., Petersen, E. S., Cunningham, D. J. C., and Sleight, P. (1972). Effects of autonomic blockade on the baroreflex in man at rest and during exercise. Circulation Research, 30, 177-185.

Pine, M., Favrot, L., Smith, S., McDonald, K., and Chidsey, C. A. (1975). Correlation of plasma propranolol concentration with therapeutic response in patients with angina pectoris. Circulation, 52, 886-893.

Prichard, B. N. C., and Gillam, M. S. (1966). Propranolol in hypertension. American fournal of Cardiology, 18, 387-391.

Simon, G., Kiowski, W., and Julius, S. (1977). Effect of betaadrenoceptor antagonists on baroreceptor reflex sensitivity in hypertension. Clinical Pharmacology and Therapeutics, 22, 293-298.

Smyth, H. S., Sleight, P., and Pickering, G. W. (1969). Reflex regulation of arterial pressure during sleep in man: quantitative method of assessing baroreflex sensitivity. Circulation Reszarch, 24, 109-121.

Requests for reprints to Dr R. T. Krediet, Universiteitskliniek voor Inwendige Ziekten, Binnengasthuis, Grimburgwal 10, Amsterdam, The Netherlands. 